\title{
PAPR reduction in OFDM system for DVB-S2
}

\author{
Zainab M. Abid, Awatif A. Jafaar, Suha Q. Hadi \\ Department of Electrical Engineering, College of Engineering, Al Mustansiriyah University, Iraq
}

\begin{tabular}{l}
\hline \hline Article Info \\
\hline Article history: \\
Received Apr 18, 2019 \\
Revised Jun 20, 2019 \\
Accepted Jul 9, 2019 \\
\hline Keywords: \\
DCT \\
Interleaver \\
LDPC \\
OFDM \\
PAPR \\
$\mu$-law companding
\end{tabular}

\begin{abstract}
A special form of multicarrier modulation is Orthogonal Frequency Division Multiplexing (OFDM) which is offer high spectral efficiency for high speed data transmission through multipath fading channels. Many advantages can be achieved by using OFDM in addition to spectral efficiency like its robustness against intersymbol interference and multipath effect. One of a major drawback of OFDM is high Peak-to-Average Power Ratio (PAPR) of the transmitted signal which leads to a distortion in the power amplifier and causes decreasing the efficiency of power amplifier. To reduce PAPR of OFDM signal many of promising solutions have been proposed and implemented. In this paper, a joint Low Density Parity Check code (LDPC), Discrete Cosine Transform (DCT) and $\mu$-law companding is proposed to reduce PAPR of OFDM signal at transmitter. Comparison of these PAPR reduction techniques is done based on CCDF performance of the system.
\end{abstract}

Copyright $@ 2020$ Institute of Advanced Engineering and Science. All rights reserved.

\section{Corresponding Author:}

Zainab M. Abid,

Department of Electrical Engineering,

College of Engineering,

Al Mustansiriyah University, Iraq.

Email: zainab.majeed@umoustansiriyah.edu.iq

\section{INTRODUCTION}

Day by day, OFDM become more popular in many wired and wireless applications. The idea of OFDM system is concentrated on the division of the bandwidth into narrow orthogonal sub channel. The high PAPR is one of the disadvantages in OFDM system. The high PAPR causes in band and out band distortion which lead to nonlinear distortion. Many approaches have been proposed to reduce PAPR. The simplest one is the clipping technique which is considered as distortion because it have some loss in power and degradation in Bit Error Rate (BER) [1], selected mapping (SLM) technique [2]. Error correcting codes are also used to improve the performance of OFDM system like Low Density Parity Check code (LDPC) in [3], Hamming code and convolutional code in [4] and Turbo code in [5]. In [6], the authors used $\mu$-law companding transform to examine its effect on the PAPR reduction. In reference [7], DCT is used before the IFFT to minimize the autocorrelation of the input data and hence to reduce the PAPR. The authors in $[8,9]$ examined the effect of concatenation of the DCT and companding transform on the PAPR of OFDM system. This paper proposes an efficient system based on a joint LDPC, DCT and $\mu$-law companding technique for reducing the PAPR in OFDM system.

\section{PAPR}

One of the major disadvantages of the OFDM system is the high PAPR. This high value of PAPR is due to the large number of subcarrier in OFDM system. For this reason, the peak value will be high as compared with the average value and this causes high PAPR [10]. This high value causes degradation in the performance of power amplifier because it causes high back off at power amplifier in order to ensure that the last operates at a linear region so the high PAPR will make the power amplifier to operate inefficiently. 
The PAPR can be defined as the ratio between the maximum power and average power in one OFDM symbol as shown below:

$$
P A P R=\frac{\max (x(k))^{2}}{E(X(K))^{2}}
$$

where $\mathrm{E}(\mathrm{)})$ is the expectation operator of random signal [11].

To analyze the PAPR in OFDM system, the complementary cumulative distribution function $(\mathrm{CCDF})$ is used. CCDF describe the probability where PAPR exceeds certain threshold values [12].

$$
\begin{aligned}
& C C D F=\operatorname{Probability}\left(P A P R>P_{0}\right), \quad \text { where } P_{0} \text { is the threshold value. } \\
& C C D F=1-\left(1-\exp \left(-P_{0}\right)\right)^{N}, \quad \text { where } N \text { is the number of carrier. }
\end{aligned}
$$

\section{LDPC CODES}

Since the 1949 when Shannon presented the theoretical limit of error correcting codes, many of codes were proposed, but did not reach to the ideal limit until the turbo coding system. In 1962, a new class of error correcting code was proposed by Gallager to have performance near of Shannon limit. This code is known as Gallager code which is now known as LDPC code. The LDPC code was capable of achieving a good performance by designing a parity check matrix $H$ with a few '1's spread among many '0's and by presenting an iterative decoding technique. There are two types of LDPC codes depending on the number of ' 1 's in rows and columns. If the number of ' 1 's is to be constant in row and column then this type is known as regular LDPC codes. However, if the number of '1's is varied then this is said to be irregular LDPC codes.

$$
H=\left[\begin{array}{llllllll}
0 & 1 & 0 & 1 & 1 & 0 & 0 & 1 \\
1 & 1 & 1 & 0 & 0 & 1 & 0 & 0 \\
0 & 0 & 1 & 0 & 0 & 1 & 1 & 1 \\
1 & 0 & 0 & 1 & 1 & 0 & 1 & 0
\end{array}\right]
$$

Although the BER performance of the turbo code is close to Shannon limit, but the LDPC achieves performance better than this code. As previously mentioned, the LDPC code can be implemented as irregular code which is operating in $\mathrm{GF}(\mathrm{q})$, where $\mathrm{q}=4,8$ and 16 gives better performances and it is preferred in many current applications [13].

\section{DCT}

The DCT is similar to Discrete Fourier Transform (DFT), but it uses real numbers only and the length of DCT is twice the length of DFT. DCT was proposed by Ahmed et al. (1974). Using this transform reduces the autocorrelation of the input sequence and this reduces the PAPR [14].

$$
x(k)=a(k) \sum_{n=0}^{N-1} x(n) \cos \left(\frac{(2 n+1) \pi k}{2 N}\right), \quad \text { For } \mathrm{k}=0,1, \ldots \ldots, N-1
$$

where,

$$
\begin{aligned}
& a(k)=\sqrt{\frac{1}{N}}, \quad \text { if } \mathrm{k}=0 \\
& a(k)=\sqrt{\frac{2}{N}}, \quad \text { if } \mathrm{k}=1,2 \ldots \ldots \mathrm{N}-1
\end{aligned}
$$

The inverse DCT at the receiver is obtained according to the following equation:

$$
x(n)=a(k) \sum_{k=0}^{N-1} x(k) \cos \left(\frac{(2 n+1) \pi k}{2 N}\right), \quad \text { For } \mathrm{k}=0,1, \ldots \ldots, N-1
$$




\section{COMPANDING TRANSFORM}

Companding transform technique is considered as amplitude limiting technique. The idea of this technique is by amplifing the lower peak signal while period of higher peak signal will be attenuated, so the average power will increase and hence the PAPR decreases. In reference [15], the authors presented system uses linear companding transform where two inflexion points are used to increase the flexibility of the companding design. The authors in [16] examined the effect of a nonlinear companding transform to reduce PAPR in OFDM system using error function to increase the average power and hence reducing PAPR.

In this paper, $\mu$-low companding technique is used which is considered as nonlinear mechanism to reduce PAPR. The mathematical formula of the output signal for companding and decompanding techniques are $D(x)$ and $\bar{D}(x)$, respectively as shown below:

$$
\begin{aligned}
& D(x)=\frac{v}{\log (1+\mu)} \log \left(1+\frac{\mu}{v}|x|\right) \operatorname{sgn}(x) \\
& \bar{D}(x)=\frac{v}{\mu}\left(e^{\frac{|r| \log (1+\mu)}{v}}-1\right)
\end{aligned}
$$

where $v$ is the maximum value of the signal, $x$ is the baseband OFDM signal, $\mu$ is the companding parameter and $r$ is the received signal at the receiver [17].

\section{INTERLEAVED OFDM TECHNIQUE}

This technique is also used to reduce PAPR in OFDM system. Interleaver is a device that reorders the symbols in a specific manner; i.e. the symbol sequence $\mathrm{X}=\left(X_{0}, X_{1}, \ldots, X_{N-1}\right)$ becomes after interleaving $X^{\prime}=\left(X_{\pi(0)}, X_{\pi(1)}, \ldots . X_{\pi(N-1)}\right)$. In this technique (M-1) interleavers are used in front of the block of IFFT. Each interleaver produces a different output frame for the same information input and then at the output of IFFT block, the one with lowest PAPR will be chosen. Both transmitter and receiver should store the permutation indices in their memory to retrieve the original data [18]. The block diagram of this technique is shown in Figure 1.

In this paper, a random interleaver is used with for PAPR reduction. The random interleaver is a block interleaver with length $N$ which permute the symbols in pseudo random order and the system is evaluated by the comparison with the other proposed system.

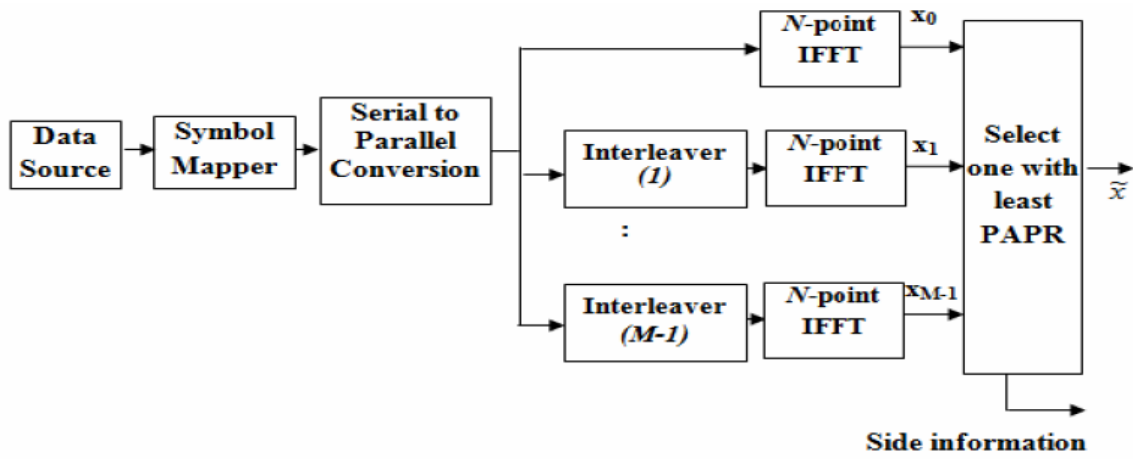

Figure 1. Interleaved OFDM technique

\section{THE PROPOSED SYSTEM}

The proposed system combined LDPC code, DCT and $\mu$-law companding transform to the PAPR reduction. In this system, the standard DVBS2 is used. The rate of $\mathrm{LDPC}=1 / 4, \mu$-law companding transform is used to enhanced the performance of beside of LDPC code. DCT is added to reduce the autocorrelation of the input stream. The steps of the proposed system are shown in Figure 2 and described as below:

Step 1: the input bits are encoded using LDPC code.

Step 2: the coded stream is modulated by Binary phase shift keying (BPSK).

Step 3: the coded modulated data is transformed using DCT. i.e, $y=$ DCT $(X)$

Step 4: the previous output from DCT is applied to IFFT. i.e, $y=[y(1), y(2), \mathrm{y}(3), \ldots \ldots y(N)]^{N}$. 
Step 5: $\mu$-law companding transform is used (compression in transmitter and expanding in receiver). i. e., $\mathrm{S}$ $(\mathrm{n})=\mathrm{C}(\mathrm{y}(\mathrm{n}))$.

Step 6: adding cyclic prefix then transmit the signal through the channel.

Step 7: removing cyclic prefix from received signal.

Step 8: expanding the previous signal $r(n)$ as a process of inverse companding transform.

$$
\hat{y}(n)=C^{-1}\{r(n)\}
$$

Step 9: FFT transform is applied to the signal. i.e., $\mathrm{y}^{\wedge}=\operatorname{FFT}\left[\mathrm{y}^{\wedge}(\mathrm{n})\right]$.

where: $\mathrm{y}^{\wedge}=\left[\mathrm{y}^{\wedge}(1), \mathrm{y}^{\wedge}(2), \mathrm{y}^{\wedge}(3), \ldots \ldots . . \mathrm{y}^{\wedge}(N)\right]^{T}$

Step 11: the signal $\mathrm{X}^{\wedge}$ is decoded using LDPC decoder using sum product algorithm.

Step 12: the decoded signal is demodulated to obtain the output bit stream.

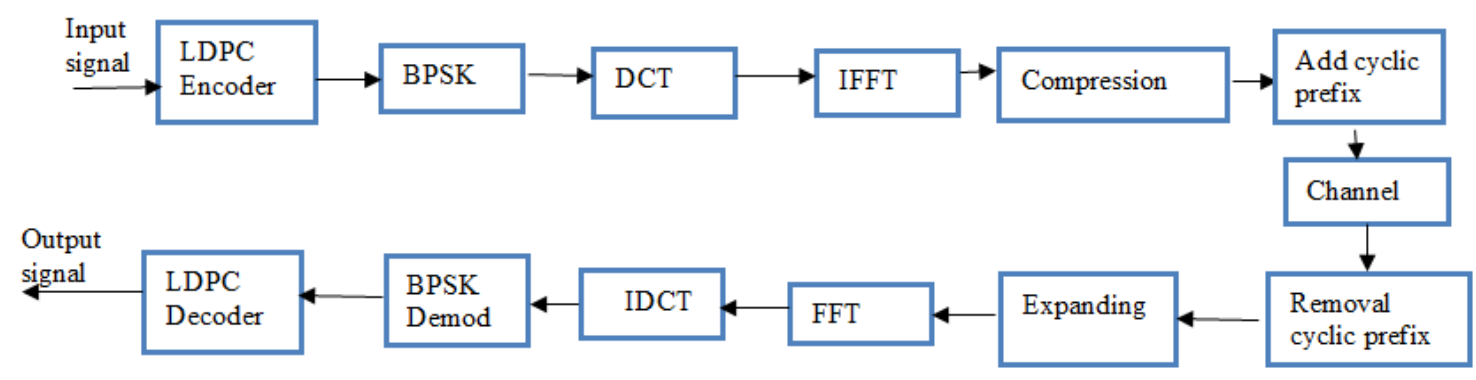

Figure 2. Block diagram of the proposed system

\section{CCDF PERFORMANCE OF THE PROPOSED SYSTEM} with $N=64$.

Figure 3 shows the results of PAPR of the simulated OFDM system with the theoretical case

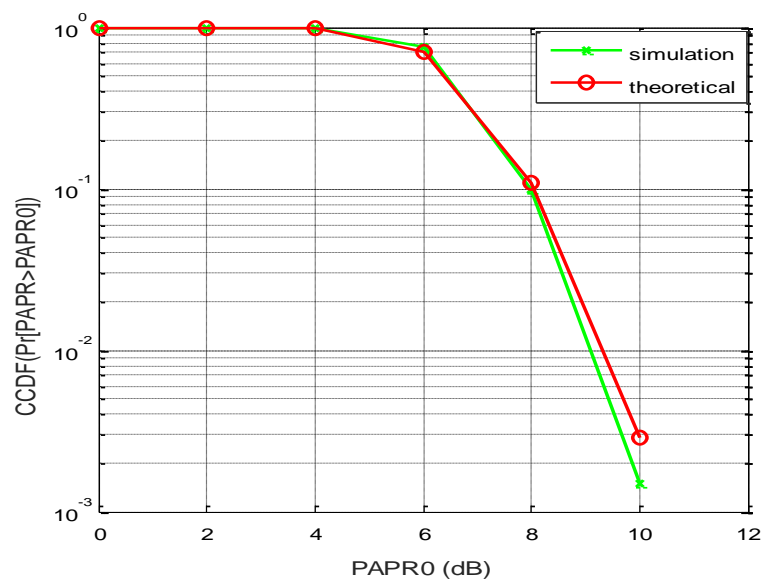

Figure 3. Comparison of the CCDF calculation for simulated OFDM system and theoretical case

Figure 4 describes the CCDF performance of different PAPR reduction schemes in frequency selective channel of DVBS2 systems. The comparison is done between the original OFDM system, the scheme that used DCT as a reduction technique for PAPR, $\mu$-law companding transform technique with companding parameter $=5$ and joint scheme of DCT with companding transform.

Figure 5 shows the improvement in PAPR for the proposed system with three cases: if only LDPC code is used to reduce the PAPR, if LDPC code and DCT are used and if the $\mu$-law companding transform after IFFT is added to the previous two methods. As shown from this figure, the reduction in PAPR is about $6.5 \mathrm{dbB}$ for the proposed system with companding parameter $=5$. 


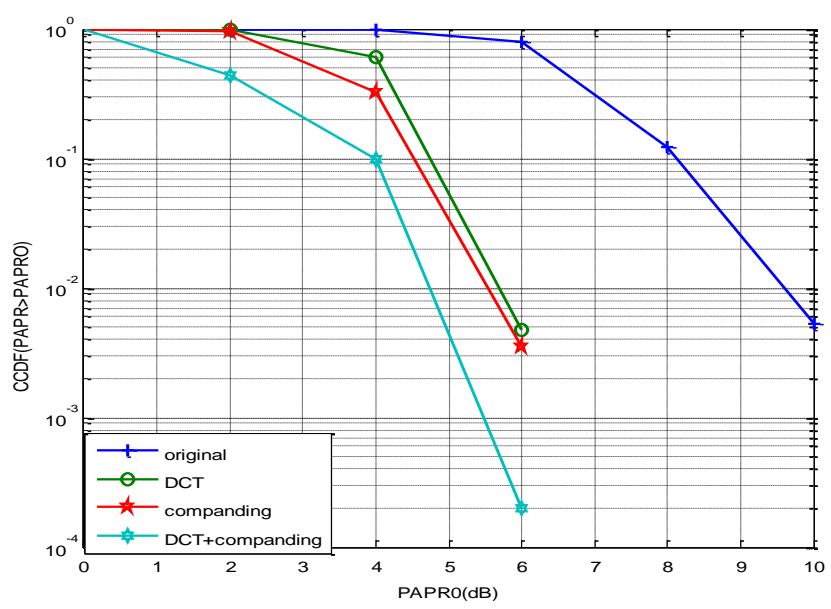

Figure 4. Comparisons of different PAPR reduction systems and proposed system

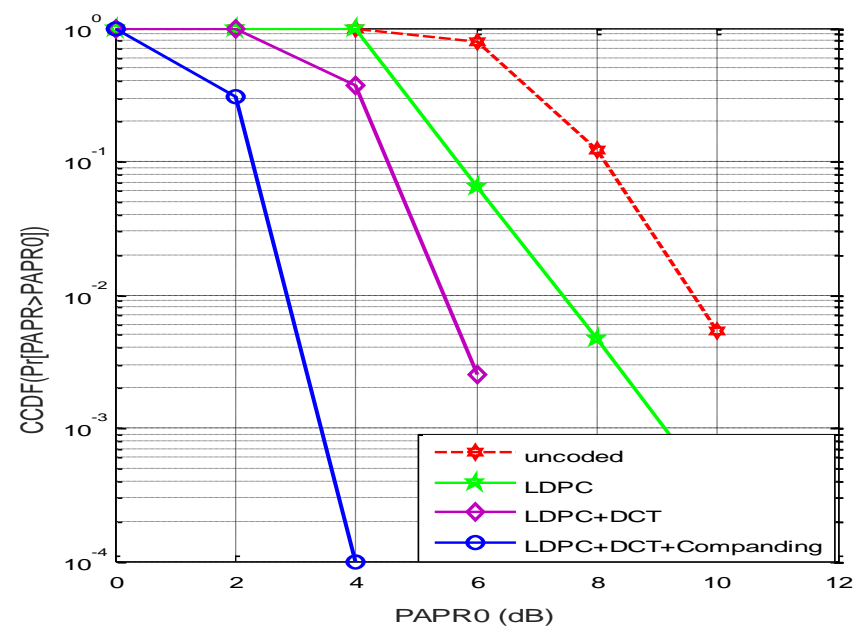

Figure 5. Comparisons of different PAPR reduction systems and proposed system

Figure 6 presents the effect of companding parameter on the PAPR improvement for the proposed scheme. It can be seen that as companding parameter increases, the reduction of PAPR will be increase.

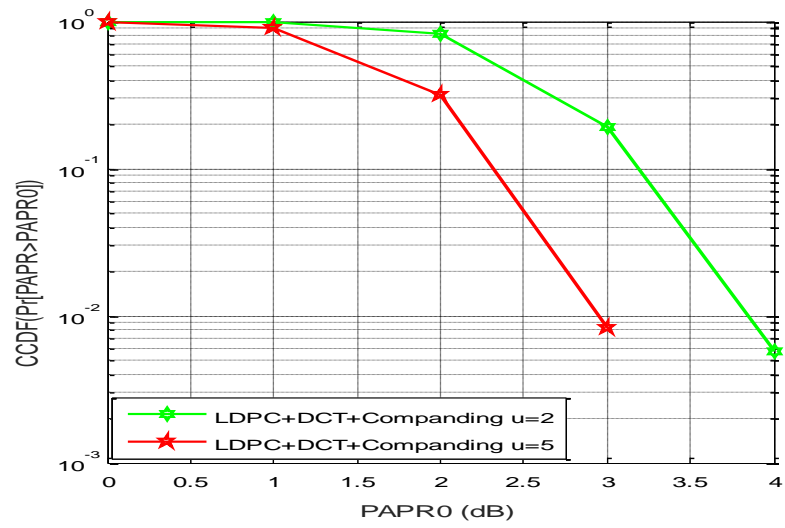

Figure 6. Comparisons of CCDF in different compounding parameter 
Figure 7 present the simulation results for the original OFDM system and the interleaved OFDM technique for three random interleavers. As shown from this figure, the interleaved system achieves PAPR reduction about $1.5 \mathrm{~dB}$ compared with the original system. Figure 8 shows the comparison between the proposed systems and the conventional PTS (C-PTC) in reference [19] to verify the performance of the proposed systems.

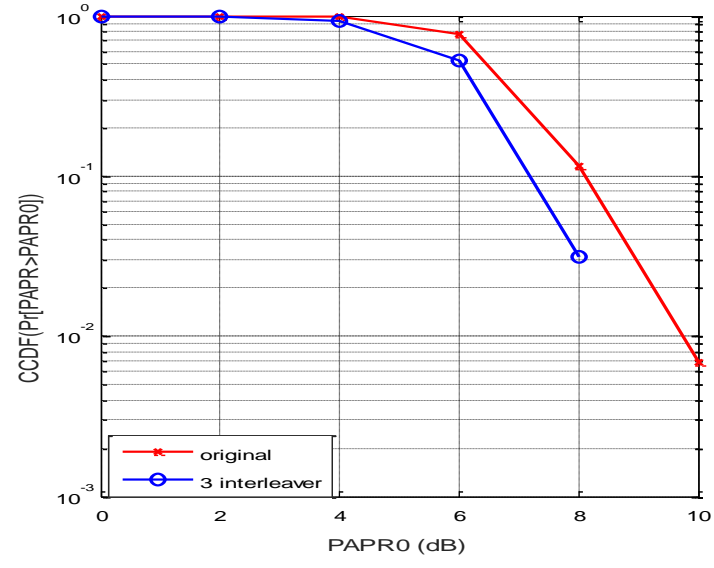

Figure 7. Comparisons of CCDF for interleaved and original systems

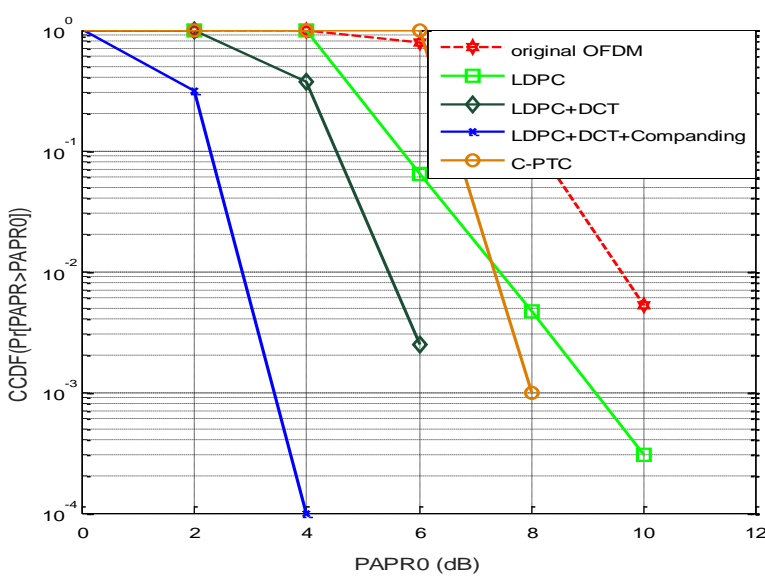

Figure 8. CCDF's Comparison of the proposed systems and C-PTC method

Comparison results have shown that the proposed systems achieve about $4.2 \mathrm{~dB}$ PAPR reduction for joint LDPC,DCT and $\mu$-law companding scheme and about $2 \mathrm{~dB}$ for LDPC with DCT scheme.

\section{CONCLUSIONS}

In this paper, we proposed a joint LDPC and DCT with $\mu$-law companding system to reduce the PAPR of OFDM signals. In the first step, the PAPR reduction is achieved by DCT and companding techniques then the proposed system with LDPC code is examined. Another scheme has been tested also by using interleaved technique. To evaluate the improvement of the proposed system, an interleaved system have been tested. This scheme gave about $1.5 \mathrm{~dB}$ PAPR reduction which is considered modest value comparing with the results of the proposed system. Simulation results show that the PAPR reduction is improved for the proposed joint DCT, LDPC and companding techniques when compared with DCT, companding and interleaved technique. Furthermore, comparison results have show that the proposed systems give PAPR reduction higher than that of the C-PTC system in reference [19].

\section{REFERENCES}

[1] Kim J, Shin Y. An effective Clipping Companding scheme for PAPR Reduction of OFDM Signal. IEEE International Conference on Communications, Beijing. 2008; 668-672.

[2] Kargozar F, Nilashi M, Ibrahim O. SLM Technique Combined with a Random-Like Coding for Reducing PAPR in OFDM Systems with No Explicit Side Information. International Journal of Information and Electronics Engineering. 2013; 3(3).

[3] Juwono FH, Triprasetyo Y, Gunawan D. Exploiting LDPC Codes for Improving the Performance of ClippedOFDM System. International Journal of Technology. 2013; 2086-9614.

[4] Nagarjuna T, S.Lakshmi, K.Nehru. BER Analysis of Concatenated Levels of Encoding in GFDM System Using Labview. Indonesian Journal of Electrical Engineering and Computer Science. 2019; 14(1): 80-91.

[5] Sameer A. Malek. Anuar. Rahim. Enhancement the Performance of OFDM Based Multiwavelets Using Turbo Codes. TELKOMNIKA Journal of telecommunication, computing, control and electronics. 2015;13(4): 1225-1232.

[6] Wang X, Tjhung TT, Ng CS. Reduction of Peak-to-Average Power Ratio of OFDM System Using a Companding Technique. IEEE Trans. Broadcast. 1999; 45(3): 303-307.

[7] Zhu XD, Zhu G X, Jiang T. Reducing the Peak-to- Average Power Ratio Using Unitary Matrix Transformation. IET Communications. 2009; 3(2): 161-171.

[8] Wang Z. Combined DCT and Companding for PAPR Reduction in OFDM Signals. Journal of Signal and Information Processing. 2011. 
[9] Muralibabu K, Naidu KR, Padmanabhan S, kumar GP. PAPR Reduction Using Combined LDPC and DCT with Companding Transform in OFDM System. International Journal of Engineering Research and Development. 2012; 3(12): 33-38.

[10] Arpit M, Puneet K, Neelu T. PAPR Reduction in OFDM System by Using Discrete Cosine Transform and $\mu$-law Companding. IJCSE International Journal of Computer Sciences and Engineering. 2015; 3(6): 22-25.

[11] Iram M, Norulhusna A, Hazilah M, Mohd, Norliza M. PAPR Reduction Techniques in Generalized Inverse Discrete Fourier Transform Non-orthogonal Frequency Division Multiplexing System. Indonesian Journal of Electrical Engineering and Computer Science. 2018; 10(3): 1045-1052.

[12] Aquino GP, Mendes LL. PAPR Reduction and Performance Improvement in OFDM Systems Using WHT-Based Schemes. Journal of Communication and Information Systems. 2017; 32(1).

[13] Moreira JC, Farrell PJ. Essential of Error Control Coding. India: Wiley; 1 edition. 2010.

[14] Sujatha S, Jayshri R, Dananjayan P. PAPR Reduction for OFDM System using DCT Based Modified PTS Technique. International Journal of Communications. 2016; 1:36-49.

[15] Aburakhia SA, Badran EF, Mohamed DAE. Linear Companding Transform for the Reduction of Peak-to-Average Power Ratio of OFDM Signals. IEEE transactions on broadcasting. 2009; 55(1).

[16] Jiang T, Zhu G. Nonlinear Companding Transform for Reducing Peak-to-Average Power Ratio of OFDM Signals. IEEE Trans. Broadcast. 2004; 50(3): 342-346.

[17] Ali N, Almahainy R, Al-Shabili A, Almoosa N, Abd-Alhameed R. Analysis of Improved $\mu$-Law Companding Technique for OFDM Systems. IEEE Transactions on Consumer Electronics. 2017; 63(2).

[18] Jayalath ADS, Tellambura C. The Use of interleaving to Reduce Peak to Average Power Ratio of an OFDM Signal. IEEE Global Telecommunications Conference, San Francisco. 2000; 82-86.

[19] Hocine A, Jean-Y, G. A PAPR Reduction for OFDM Signals Based on Self-Adaptive Multipopulation DE algorithm. International Journal of Electrical and Computer Engineering (IJECE). Vol. 7, No. 5, October 2017, pp. $2651-2660$.

\section{BIOGRAPHIES OF AUTHORS}

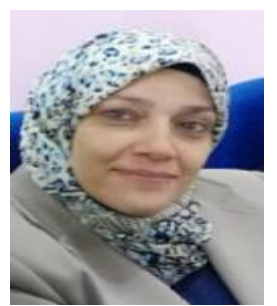

Zainab Majeed received the B.Sc. \& M.Sc. degree in Electronic and Communication Engineering from Baghdad University, Iraq in 1993 and 2010 respectively. She is presently working as an Assistant Lecturer in the Department of Electrical Engineering in al Mustansiriyah University College of Engineering, Iraq. Her areas of research include OFDM, CDMA and Multi Carrier CDMA technologies \& Wireless Communications.

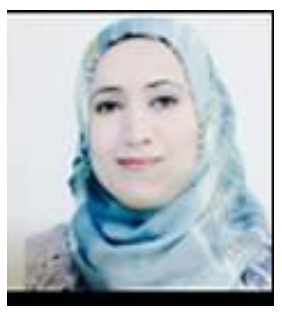

Awatif Ali Graduated from Almustansiriyah university in 1993 with BSc in Electrical Engineering. She received her Master degree of Electrical Engineering in 2009. Currently, she is a lecturer at electrical engineering department, Almustansiriyah university. Her expertise is on the area of digital signal processing and wireless communication. Her research interests are on future communication such as $5 \mathrm{G}$ and focusing on error correcting codes, turbo codes, LDPC codes, OFDM and steganography.

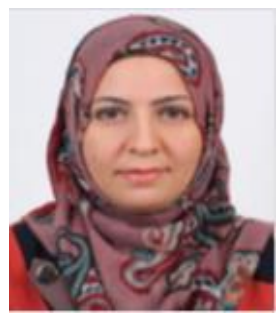

Suha Q. Hadi received the B.Sc. degree in Electrical Engineering from Al-Mustansiriyah University (Iraq-2006), and the M.Sc. degree in Electronic and Communication Engineering from Al-Mustansiriyah University (Iraq-2009), and the PhD in Communication Engineering from School of Computer and Communication Engineering, Universiti Malaysia Perlis (UniMAP) (Malaysia-2017). Currently, she is a lecturer at Al-Mustansiriyah University, College of Engineering. Her research interests focus on wireless communication with emphasis on, mobile wireless communications, multicarrier modulation system, and fourth generation (4G) systems. 